Ramon, X., \& Rojas-Torrijos, J.L. (2021). Public service media, sports, and cultural citizenship in the age of social media: An analysis of BBC Sport agenda diversity on Twitter. International Review for the Sociology of Sport. Online first. https://doi.org/10.1177/10126902211043995

\title{
Public service media, sports, and cultural citizenship in the age of social media: An analysis of BBC Sport agenda diversity on Twitter
}

\author{
Xavier Ramon. Department of Communication, Universitat Pompeu Fabra \\ José Luis Rojas-Torrijos. Department of Journalism II, University of Seville
}

As a crucial part of their mandate, public service media (PSM) have historically used sports to construct and nurture cultural citizenship. In a landscape characterised by dwindling resources and growing competition from pay-TV channels and on-demand streaming services, concerns about how PSM will enhance cultural citizenship through new platforms, including social media, are all the greater. In the digital age, delivering diverse content should remain a foundation of PSM in their countless platforms: public media should not only concentrate on major sports but also provide exposure to traditionally underrepresented disciplines and individuals, including sportswomen and athletes with disabilities. Through content analysis, this research examines the agenda diversity offered by the British Broadcasting Corporation (BBC) through its sportscentred Twitter account (@BBCSport). The analysis of 10,821 tweets indicates how the $\mathrm{BBC}$ 's content reinforces, rather than counteracts, the long-standing diversity imbalances in the analogue age. This case study facilitates an understanding of the nuanced relationship between PSM, social media, and sports, demonstrating that more content does not necessarily ensure diversity. The football-driven, male-centred, and able-bodied agenda displayed by @BBCSport signals that PSM should reframe their social media strategies to adequately contribute to fostering cultural citizenship.

Keywords: Public service media, sports and cultural citizenship, sports media, agenda diversity, social media, Twitter, sportswomen, disability 
As a crucial part of their mission, public service media (PSM) have historically used sports to construct and nurture cultural citizenship. As noted by Hermes (2005: 4), the concept of cultural citizenship refers to the 'less formal everyday practices of identity construction, representation, and ideology, and implicit moral obligations and rights'. Stevenson (2003: 33) emphasises that cultural citizenship relates to 'rights and obligations, civic spaces of participation, respect, identity and difference, and individualisation'. In the sports field, cultural citizenship can be defined as 'the rights and responsibilities regarding access to, and representation in, sports culture' (Rowe, 2018: 12).

PSM perceive sports as a vital component that enables 'the full participation of citizens in the collectively oriented public culture environments that constitute the social' (Hutchins et al., 2019: 989). Free-to-air broadcasting of sports has allowed PSM 'to bring communities and/or the nation together, as well as to reach audiences that are otherwise often underserved by PSBs' (Smith, 2017: 203-204). By embodying the values of cultural citizenship, public broadcasters have been important agents for showcasing major sporting events and for exposing sporting practices woven into the cultural fabric of nations (Ramon and Haynes, 2019; Røssland, 2017; Scherer and Sam, 2012; Scherer and Whitson, 2009).

However, PSM's use of sports programming to enhance cultural citizenship through linear broadcasting is increasingly threatened by major challenges arising from digitisation, globalisation, and commercialisation (Hesmondhalgh and Lotz, 2020). As Rowe (2018: 25) highlights, 'the very idea of the public, as opposed to that of the market, is under severe pressure'. The escalating cost of sports rights, currently controlled by global telecommunications and media corporations, has 'undermined the ability of public broadcasters to cover major sporting competitions and leagues' (Ramon and Haynes, 2019: 223). As illustrated by the situation in countries as diverse as Canada, India, Indonesia, New Zealand, South Africa, and the United Kingdom, public broadcasters are struggling to maintain free-to-air access to sports coverage (Cwynar, 2017; Masduki, 2017; Scherer and Sam, 2012; Scherer and Whitson, 2009; Smith, 2016; Smith, 2017).

Despite such pressing challenges, PSM should restore their commitment to diversity by placing a 'renewed emphasis on noncommercial programming in areas often neglected by the commercial media' (Cwynar, 2017: 135). As a crucial component of cultural citizenship, diversity entails making various 'societal groups visible in their coverage' and informing people 'about a wide range of issues, including niche topics' 
(Steiner et al., 2019: 102). In the sports field, diversity not only implies providing access to 'the most important sports presented in the best possible way' (Rowe, 2004: 387) but also exposes traditionally underrepresented sports and protagonists, including sportswomen and athletes with disabilities. By adopting an inclusive approach, PSM can play a distinctive role by transcending the uniformity, repetition, and overwhelming lack of diversity that routinely characterises sports media output (English, 2018).

As noted by Pawley (2008: 601), cultural citizenship 'must be continually stated, practised, and negotiated'. Thus, the concept of cultural citizenship should be subjected to renewed attention in the digital age. New technologies have the potential to advance cultural citizenship (Hermes, 2020; Wu, 2013), but their usage also raises important questions about 'access, visibility, and cultural recognition' (Goode, 2010: 527). Beyond the offline world, the multiplication of platforms and channels 'affords a degree of cultural oxygen' (Goode, 2010: 533) to various individuals, groups, and practices. However, the existence of these new spaces does not automatically 'translate into a guarantee of greater visibility or recognition' (Goode, 2010: 532) for them. Given that cultural citizenship should be conceptualised 'in terms of the ownership and control of the means of cultural production' (Turner, 2001: 20), it is particularly important to interrogate how public owned media are leveraging new technologies to warrant recognition to diverse collectives and manifestations within the field of sports.

In the age of 'digital plenitude' (Hutchins and Rowe, 2009), technological affordances provide new opportunities for PSM to distribute their content through an expanding array of platforms, services, and applications (Van Es and Poell, 2020). PSM can benefit from digital platforms to strengthen 'cultural identity and diversity, social cohesion, media literacy, emancipation, information citizenship, and so on' (Donders, 2019: 1014). In the sports field, platforms such as Twitter offer new opportunities to broaden the agenda, deliver high-quality sports content, and engage with new audiences (Rojas-Torrijos and Ramon, 2021). However, a key question is: Are social media platforms leveraged to promote sports diversity and, therefore, enhance cultural citizenship?

In light of these broader transformations and tensions, this research aims to contribute to this ongoing debate by examining the agenda diversity offered by the British Broadcasting Corporation (BBC) through its sports-centred Twitter account (@BBCSport). This article, first, endeavours to scrutinise the historical relationship between the $\mathrm{BBC}$ and sports, considering the essential role of the $\mathrm{BBC}$ in promoting 
cultural citizenship through sports programming. Attention will thus turn to long-standing imbalances in the sports communication field, highlighting the potentially transformative role that social media can play in counteracting such inequalities. The analysis of 10,821 tweets considers how the BBC's content reinforces, rather than counteracts, the longstanding diversity imbalances present in the analogue age. This case study facilitates an understanding of the nuanced relationship between PSM, social media, and sports, demonstrating that more content does not equate to enhanced visibility of minority disciplines, sportswomen, and athletes with disabilities. The insights gleaned from the analysis signal that, in an increasingly commercialised environment, PSM should reframe their social media strategies to adequately contribute to fostering cultural citizenship.

\section{BBC and sport: An enduring relationship}

Founded in 1922 as the British Broadcasting Company and replaced in 1927 by the British Broadcasting Corporation, the $\mathrm{BBC}$ has always sought to 'provide quality programmes for its audiences across all genres, including the kinds of popular programming where the BBC's impact on the broadcasting market is most likely to be felt' (Goddard, 2017: 1091). From its inception, the BBC 'positioned sport as an integral part of a particular view of national culture that the $\mathrm{BBC}$ was bound to promote, protect and reflect back to the "nation"” (Boyle, 2006: 60).

Outside broadcasting of sporting events made its debut in BBC radio's output in 1927. During the first year, the BBC presented audiences with a breadth of live sporting experiences, including coverage of the Grand National horse race, the Oxford v. Cambridge Boat Race, Rugby Union, Wimbledon, and amateur golf (Smith, 2017; Whannel, 2009). In the 1930s, the BBC broadened the spectrum to cover 'examples of less participatory sports such as basketball, clay pigeon shooting, cross-country championships, darts, fencing, gliding, pigeon racing, point-to-points, power-boat racing, racquets, real tennis, rifle shooting, speedway, table tennis, and snooker' (Huggins, 2007: 499-500). Thanks to this approach, the BBC 'introduced listeners to sports they might never previously considered watching or reading about and further widened the audience' (Huggins, 2007: 500). While sports coverage helped to attract female listeners, it should be noted that 'women's sport apart from tennis received far less radio coverage than it did on the various cinema newsreels or in the print media' (Huggins, 2007: 506).

Subsequently, the introduction of televised broadcasts in 1937 contributed to shaping the BBC's unique position as 'the home of sport'. During the era of the monopoly 
of broadcasting (1922-1955), the BBC's 'coverage of major sporting occasions both reinforced and to a degree reconstructed a calendar of principal events that came to constitute the sporting year' (Whannel, 1992: 11). Huggins (2007: 493) emphasises that with the creation of such a calendar, the BBC 'promoted social unity rather than rivalry' while manufacturing "norms and expectations about commentaries alongside BBC cultural values and attitudes'. With its extensive coverage of the 1948 Olympic Games, the $\mathrm{BBC}$ further revealed itself as a 'key player in the endorsement of major sporting events, and why they were of importance to the British public' (Haynes, 2016: 72). Nevertheless, during the formative years of BBC sport in television, women remained marginalised, both in terms of coverage and presence of female commentators (Haynes, 2016).

In the 1950s, the BBC introduced its flagship programmes Sportsview (19541968) and Grandstand (1958-2007). In a context characterised by the end of the 'monopoly era' and the launch of ITV, the BBC innovated, developing magazine formats that contributed to attracting new audiences. To educate viewers, Sportsview provided space for regional content and women's sports, diversified the range of disciplines covered, and developed an appreciation for international sports (Haynes, 2016). As noted by Haynes (2016: 125), 'although the volume of women's sport may have suffered in comparison to the coverage of men's, there is evidence to suggest Sportsview took women's sport seriously, challenging the dominant views of the period.' Grandstand's pioneering approach combined up-to-the-minute news with live broadcasts. While attracting family audiences, the program offered a regular diet of televised sporting experiences, including horseracing, football, rugby, golf, boxing, and motorsports (Haynes, 2016; Haynes and Robeers, 2019).

The next decade was marked by the advent of BBC 2, which allowed for more sports to be incorporated into the schedules (Whannel, 2009). The launch of football analysis was another landmark and highlighted the program Match of The Day (1964). The coverage of the 1966 FIFA World Cup, coupled with technological innovations such as the introduction of colour cameras in 1967, further contributed to strengthening the BBC's leadership position in the sports broadcasting field (Haynes, 2016: 290-312). Female athletes gained respectability on television as the BBC celebrated the successes of British elite sportswomen in a major event like the Olympics (Kay, 2010). However, the attention on athletes with disabilities remained minimised. To illustrate, it was not 
until Arnhem 1980 that the BBC produced a specific programme about the Paralympic Games in the form of a 60-minute documentary (Brittain, 2012: 143).

During the 'duopoly era' of the 1970s and 1980s, the BBC recognised that sport, 'while part of its wider national cultural remit, was also an important area of output regarding attracting an audience, often outwith of peak viewing times' (Boyle, 2006: 66). The BBC continued to provide audiences with more sports hours than ITV and Channel 4, although this did not necessarily translate into more diversity regarding gender and the range of disciplines highlighted (Whannel, 1992: 82-85).

In the 1990s, the BBC's leadership position was significantly affected by the inflation of rights fees as 'ITV and the satellite broadcaster BSkyB pushed the cost of sports rights out of the reach of the Corporation' (Boyle, 2006: 70-71). Competition for sports rights has not receded since then and is currently dominated by pay-TV giants Sky, British Telecom (BT), and Amazon. These global companies hold an extensive range of top-tier rights, including the Premier League, Formula 1, the UEFA Champions League, the Europa League, Premiership Rugby, Moto GP, ATP, and WTA tennis (BT, 2019; Sky, 2018; Sweney, 2021). The escalation of rights costs, coupled with the BBC's shrinking budgets, has increasingly reduced the ability of the Corporation to offer sports free-to-air (Bailey, 2019).

As noted by Smith, the position of the BBC is 'more dependent than ever on the continued existence and effective enforcement of listed events legislation, designed to ensure that certain key national sporting events (the so-called crown jewels of sports) remain available on free-to-air television' (Smith, 2017: 209). Due to the listed events legislation, full live coverage of Group A events (The Olympic Games, the FIFA World Cup Finals Tournament, the European Football Championship Finals Tournament, the FA Cup Final, the Scottish FA Cup Final, the Grand National, the Derby, the Wimbledon Tennis Finals, the Rugby League Challenge Cup Final, and the Rugby World Cup Final) must still be offered to the BBC, ITV, and Channel 4. Group B events (including the Ryder Cup, the Six Nations Rugby, and Cricket Test matches played in England) can have live coverage on pay-TV provided that secondary coverage is offered to free-to-air broadcasters (Woodhouse, 2020).

Despite this challenging situation, BBC sport's output on television still includes live and 'as-live' sports coverage, magazine and discussion formats, preview and review programmes, and documentaries and archive-based formats. Sports news and live coverage on radio remain strong, especially because of the programming offered by BBC 
Radio 5 Live and BBC Radio 5 Live Sports Extra (BBC, 2020). Beyond legacy media, BBC's online streaming services offer 'more than 2,200 extra hours of live sport online across 54 different sports through BBC Sport and BBC iPlayer on mobile, desktop, and connected TVs' (BBC, 2019: 32).

Additionally, BBC Sport is currently present across different social media platforms, achieving high audience figures. Considering this wider visibility and support, it is of utmost importance that BBC's output on social media promotes the value of diversity. Through its social media strategy, the $\mathrm{BBC}$ can play a distinctive role by broadening the agenda and counteracting the lack of diversity that still pervades contemporary sports journalism.

\section{Diversity imbalances in the sports agenda: Disciplines, gender, and disability}

Academic literature has repeatedly remarked that the sports media agenda lacks diversity regarding sources, stories, approaches and sports covered. Sports media output also seems to reproduce and perpetuate gendered and ableist inequalities (Boyle, 2017).

\section{Underrepresented sports}

The 'advanced commoditisation and consequent hierarchisation of contemporary global sport' (Rowe, 2020: 6) directly translates into limited diversity of the sports media content. Although the representation of certain mainstream disciplines in specific countries may differ from one another regarding tradition and sporting culture (Boyle, 2006), football (or soccer) stands out as the most popular spectator sport, as well as the first widely covered discipline by media worldwide (Horky and Nieland, 2013). The 'footballization of sports journalism' (Rojas-Torrijos, 2012) implies that media outlets are more focused on one sport and, because of this, they tend to overlook other disciplines and events in their daily coverage (Ramon and Haynes, 2019; Schoch, 2020).

Mainstream sports journalism, in its efforts to satisfy fans' demands of consuming more football content, breeds an information overload of the same sport, mainly about male professional leagues and big international mega-events, while lower leagues, youth competitions, and women's games are excluded (Tulloch and Ramon, 2017). This widespread editorial approach in sports media outlets normally translates into more time and space devoted every day to a limited range of athletes and clubs that make headlines, even when fake news or non-sport content is involved. Accordingly, it is increasingly 
common to see how social media rumours and anecdotes related to footballers' private lives stand out on the agenda (Serazio, 2019).

The diversity imbalance in the sports media agenda is also caused by the frequent uniformity and similarity of its protagonists, sources, and stories. First, mainstream sports journalism appears to be reluctant to cover complex and relevant issues around tournaments (Ramon and Rojas-Torrijos, 2018), despite the boundaries between sports and social, financial and political aspects of daily life are increasingly blurred (Broussard, 2020). Conversely, sports media outlet coverage is, more often than not, focused on match-related elements and interviews with key players, coaches, or club administrators, often in a repetitive and predictable work routine (English, 2018).

\section{The gendered sports coverage}

For decades, scholarly research has deeply discussed the long-standing minimisation of sportswomen in day-to-day media coverage, highlighting that such underrepresentation is a consequence of cultural male hegemony in the sports world (Hardin, Dodd and Lauffer, 2006; Schell and Rodriguez, 2000). Across media platforms, the resulting coverage of leading female athletes and teams is still regarded as marginal compared to the frequency of appearances of their male counterparts (Coche, 2015; Cooky et al., 2021; Schoch, 2020). This gendered imbalance in the sports agenda is particularly important because it reinforces old cultural and androcentric stereotypes and acts as a barrier to promoting female role models in society (O'Neill and Mulready, 2015).

Although there is still a long way to go, the gender gap in sports performance and media representation seems to be slowly narrowing. In this sense, women have gained visibility in major sporting mega-events such as the FIFA Women's World Cup and the Olympic Games, where the amount of airtime, pages, and online space received by male and female athletes is much more balanced (Billings and Angelini, 2019; Coche, 2021).

\section{Lack of coverage of athletes with disabilities}

The lack of coverage of athletes with disabilities remains another major challenge faced by sports journalism regarding diversity. The competitive nature of sports media outlets, which are more concerned about drawing and maintaining large audiences, has led them to coverage more centred on aesthetics and pure entertainment, and rarely addresses social issues (Bertling and Schierl, 2008). Therefore, despite the increasing significance of the Paralympics as an agent for increasing disability sports participation 
and societal acknowledgment, elite athletes with an impairment remain much less visible in the media than their able-bodied counterparts (Brittain, 2017; Howe and Silva, 2018; Solves et al., 2019).

Notably, the intervention of Channel 4 in London 2012 and Rio 2016 has been instrumental in changing perceptions of disability sports (Pullen et al., 2020a; Pullen et al., 2020b). Thanks to Channel 4's broadcasting strategy, audiences have developed 'a greater appreciation of Paralympic sport as an elite sporting event' and 'an awareness of emerging cultural citizenship concerning disability rights-based discourses through greater disability media representation' (Pullen et al., 2020b: 480). This positive impact does not obscure that Channel 4's coverage has prioritised the coverage of 'big stars' from highly commodified Paralympic sports -athletics and swimming-while minimising the presence of athletes from disciplines such as archery, boccia, goalball, sitting volleyball, and equestrian (Pullen et al., 2020a).

Considering the power of media narratives to shape society's perceptions of sport, emerging social media technologies and platforms may provide new modes of consumption and opportunities for audiences to engage with athletes with disabilities (French and Le Clair, 2018), as well as for media outlets to broaden their scope and diversify their agenda.

\section{Social media and sport: A new avenue for diversity?}

The long-standing under-representation of many disciplines, female sports, and athletes with disabilities in legacy media has been largely justified by time (on TV and radio) and space restrictions (in print) (Adá-Lameira and Rodríguez-Castro, 2020) despite other factors such as the commercial orientation of sports media, assumptions about audience interests, lack of diversity in the newsrooms, and division of labour, affect editorial priorities (Schoch, 2020). However, social networking sites are not subject to time and space limitations, opening new opportunities to broaden the agenda (Hull and Lewis, 2014). The advent of social media has potentially amplified the scope of representation by 'challenging the established gate-keeping role of professional sports broadcasters and journalists' (French and Le Clair, 2018: 99).

Concurrently, social media have provoked crucial changes in media consumption patterns, with users currently demanding global content in real-time and on multiple devices. Consequently, mainstream news organisations have taken social media more seriously to explore new storytelling techniques, interact with the users, and reach wider 
audiences (Van Es and Poell, 2020). News organisations have identified on social media platforms, especially on Twitter, unlimited possibilities for audience interaction, and feedback to reframe strategies and enhance sports content.

Despite the continuing centrality of television, Twitter stands out as 'the preferred social media platform for many sports journalists and fans' (Boehmer, 2017: 303). Most Twitter events are sport-related (Hull and Lewis, 2014) and sports content, especially live events, frequently ranks among the most talked about topics on this social platform (Reichart, Pegoraro and Cruishank, 2019). Second-screen use during sports programming is on the rise, and this promotes 'a symbiotic relationship between social media and TV viewing that complement each other' (Cunningham and Eastin, 2017: 290). Arguably, a transition of premium sports content to mobile devices and social platforms such as Twitter is already underway (Lopez-Gonzalez, Stavros and Smith, 2019), and this transformation may open up the range and diversity of sports content offered by PSM.

At present, the nexus between PSM, sports content, and agenda diversity has been largely under-researched. Recently, Rojas-Torrijos and Ramon (2021) examined the sports-centred Twitter accounts of four PSM corporations across Europe: RTVE (Spain), FranceTV (France), RAI (Italy), and RTÉ (Ireland). Their analysis of 7,426 tweets over three months in 2019 revealed, 'social media platforms seem to perpetuate a fairly restricted and routinized agenda' (Rojas-Torrijos and Ramon, 2021: 236). Footballrelated tweets represented between $30-58 \%$ of the output delivered by PSM accounts. In addition to the 'footballization' of sports coverage, female athletes were protagonists in only $9.4 \%$ of the messages, while only $0.58 \%$ of the tweets referred to athletes with disabilities (Rojas-Torrijos and Ramon, 2021: 233).

Considering these findings, it is important to investigate how other PSMs employ social media to disseminate sports content. Particularly, it is important to scrutinise whether the $\mathrm{BBC}$, long regarded as 'the home of sport', leverages Twitter to promote diversity.

\section{Method}

This case study examines the agenda diversity offered by the BBC through its sports-centred Twitter handle (@BBCSport). This account was created in 2011 and currently has more than nine million followers. Three research questions guided the investigation. 
- RQ1. What is the volume and frequency of sports content published by @BBCSport on Twitter?

- RQ2. What is the agenda delivered by @BBCSport on Twitter regarding the proportion of coverage devoted to different sports, sportswomen, and athletes with disabilities?

- RQ3. Which multimedia elements are deployed by the BBC on this platform?

For this investigation, the tweets published by @BBCSport between 1 January 2020 and 31 March $2020(\mathrm{~N}=10,821)$ were examined. Each tweet was defined as an analysis unit. Posts were retrieved using Twitonomy (http://twitonomy.com), a specialised tool created by Digitonomy, which accesses data via Twitter's application programming interface (API). This tool has been recently employed in scholarly research on sports communication (Grimmer and Horky, 2018; Rojas-Torrijos and Ramon, 2021). The Twitter API can retrieve only the last 3,200 tweets published by any open account. Therefore, to ensure the retrieval of all the content published during the examined timeframe, data were extracted on 24 January 2020, 15 February 2020, 2 March 2020, and 1 April 2020.

Once Twitter posts were downloaded, they were processed using Microsoft Excel and examined through the content analysis technique. Content analysis is a research technique 'for making replicable and valid inferences from texts to the contexts of their use' (Krippendorf, 2019: 24). Content analysis, as an empirically grounded method, enables researchers to read, interpret, and make valid inferences regarding the manifest content of Twitter posts systematically. We applied this technique to tweets published by the BBC on its sports Twitter handle, to contrast the research questions (RQ1-RQ3) with the empirical data obtained (Wimmer and Dominick, 2011).

The seasonality of this sample should also be considered. In professional sports, the media agenda is defined by sports news and broadcasts of actual sports events (McCombs, 2005) and, consequently, by competition schedules. Therefore, some disciplines may attract greater media attention during particular months or weeks when major competitions are held. It should also be acknowledged that, in the last section of the sample (March 2020), the sports agenda was altered by cancellations and postponements of sports events caused by the COVID-19 pandemic. This significant disruption to the worldwide sporting calendar and athletes' lives would become a priority issue for sports media outlets, including the BBC. The research sample included March 
because competitions did not stop until the second fortnight of the month. On 12 March, the UK government considered banning sporting fixtures due to the coronavirus outbreak. However, cancellations, suspensions, and postponements of competitions progressed globally during the second half of March and the beginning of April 2020 (Horky, 2021; Parnell et al., 2020). Some Olympic qualifiers moved behind closed doors and other national rugby or football association tournaments were only suspended for a couple of weeks to restart in April. Throughout this period, @BBCSport continued to consistently report the latest updates, developments, and reactions in the field of sport.

The content analysis codebook included six variables: date of publication; type of publication (original, retweet, or reply); sports covered; gender of protagonists; disability sport or non-disabled sport; and multimedia elements included in each tweet. Before the systematic analysis of the entire sample, the two coders conducted a pre-test with 500 tweets to ensure the reliability of the category system. All six variables had a Krippendorf's $\alpha$ of above 95 .

\section{Results}

\section{Volume and frequency of content (RQ1)}

The analysis of 10,821 tweets during three months indicates that the $\mathrm{BBC}$ is consistently active on Twitter (Table 1). During the timeframe of observation, @BBCSport published 118.91 tweets per day on average, which indicates a very high volume and frequency for posting on this social platform. The account offered a continuous stream of information, which greatly capitalised on match-centred news and human-interest stories, intertwined with mentions of globally popular players, top clubs, and other stakeholders in the sports-media scenario. The Twitter handle also offered users minute-by-minute updates of events, illuminating the centrality of liveness in contemporary sports media production and consumption (Hutchins et al., 2019).

It should be noted that $19.05 \%$ of @BBCSport's messages $(\mathrm{n}=2,061)$ were retweets, drawn mainly from other BBC accounts devoted to particular sports or programs (e.g.@BBCMOTD,@5liveSport,@bbcrugbyunion,@bbcf1, and @bbctms). Replies to other users represented only $1.33 \%$ of the sample $(n=114)$.

[Table 1 near here] 


\section{Diversity agenda: Sports, gender, and disability (RQ2)}

Although in the digital age, PSM must serve 'the interests of all societal spheres to contribute to an integrated society' (Steiner et al., 2019: 112), findings reveal that sports content on Twitter strengthens long-lasting diversity imbalances in legacy media.

During the observation timeframe, the BBC posted content about 60 different sports. However, huge imbalances can be perceived in the agenda (Table 2): 62.09\% of the messages posted by @BBCSport $(\mathrm{n}=6,719)$ were football-related. Football is certainly the most practised, followed, and covered sport globally (Boyle and Haynes, 2009). The power of football content-especially from top-tier competitions such as the Premier League, the FA Cup, La Liga, Serie A, and the UEFA Champions League- is unparalleled when it comes to attracting a wide range of audiences to social media. Capitalising on its greater popularity, the BBC offered users a staple diet of football content (an average of 73.84 tweets per day), including up-to-the-minute news and commentary, live scores, interview clips, and transfer rumours.

In the second half of March 2020, major football tournaments were halted due to the coronavirus outbreak; however sports coverage in many territories remained footballdriven (Hutchins, 2020; Schallhorn and Kunert, 2020). In the case of @BBCSport, football-centrism in the agenda remained largely unaltered: from March 15 till month end, $55.62 \%$ of posts (633 out of 1,138 tweets) were focused on football.

The overload of football content, combined with prominent attention to other popular sports in the UK, such as rugby $(\mathrm{n}=878 ; 8.11 \%)$, cricket $(\mathrm{n}=747 ; 6.90 \%)$, tennis $(\mathrm{n}=450 ; 4.16 \%)$, and boxing $(\mathrm{n}=363 ; 3.35 \%)$, left little room to highlight minority disciplines. In covering those major sports, content related to the Six Nations Championship and the Super League (rugby), the 2020 ICC Women's T20 World Cup (cricket), the Australian Open (tennis), and the heavyweight fight between Deontay Wilder and Tyson Fury II (boxing) dominated the agenda.

Some traditional sports in the UK, such as athletics $(n=130 ; 1.20 \%)$, snooker ( $\mathrm{n}$ $=122 ; 1.13 \%)$, golf $(n=61 ; 0.56 \%)$, and horse racing $(n=59 ; 0.55 \%)$, were barely visible in the examined Twitter account. Forty-eight sports occupied a secondary position in the agenda, given the limited number of tweets that they received combined $(n=524)$. While lending space to international tournaments that appeal to younger demographics, such as the Ultimate Fighting Championship (UFC), the BBC devoted limited attention to competitions “closely tied to place and locality' (Rowe, 2013: 26), such as the All England Badminton Championships, the Women's British Basketball League, the World Indoor 
Bowls Championship, the Britannia Cup (figure skating), the Super 6s (hockey), and the Netball Superleague. Sparsely, the BBC exposed users to lesser-known sports such as dragon boating or yukigassen, illuminating the potential of PSM to educate audiences about diverse sporting practices and cultures across the globe.

[Table 2 near here]

The diversity imbalance in the sports agenda becomes more evident regarding the coverage devoted to sportswomen and athletes with disabilities. The enduring invisibility of both was not challenged on Twitter. Table 3 demonstrates that sportswomen were notoriously underrepresented by the BBC Sport Twitter feed, with only $10.72 \%$ of the examined tweets. In comparison, $83.62 \%$ of the messages were focused on sportsmen, while $5.66 \%$ of the tweets involved male and female athletes. Reproducing the centrality of major sports, female athletes received more exposure in football $(n=399)$, cricket $(n=253)$, tennis $(n=188)$, and rugby $(n=54)$. Such attention was linked to key tournaments like the FA Women's Super League (football), the ICC Women's T20 World Cup (cricket), the Australian Open (tennis), and the Six Nations Championship (rugby).

[Table 3 near here]

Sportspeople with any sort of impairment were marginalised in the agenda. Only 136 of the sampled tweets (1.26\%) were concerned with athletes with disabilities (Table 4). When it touched on disability, @BBCSport mainly focused on the rescheduling of the Tokyo 2020 Paralympics and the cancellation of sporting events due to the COVID-19 pandemic. Before that, limited visibility was given to athletes from different sports (table tennis, wheelchair basketball, boccia, and wheelchair rugby). Beyond team sports, the $\mathrm{BBC}$ focused on para-athletes such as Georgina Hermitage (athletics), Kadeena Cox (cycling), Millie Knight (skiing), and Grace Harvey (swimming).

While@BBCSport briefly commented on tournaments like the World Para Alpine Skiing World Cup (Kranjska Gora, Slovenia, 21-24 January) and the Wheelchair Rugby Quad Nations (Leicester, 21-23 February), other competitions such as the World Wheelchair Curling Championships (Wetzikon, Switzerland, 29 February - 7 March), the UCI Para-cycling Track World Championships (Milton, Canada, January 30 - February 2) and the Para Powerlifting World Cup (Manchester, February 20-23) were absent from 
the agenda. The retirement of the Paralympic and world running champion Paul Blake after a ten-year career was not acknowledged on BBC Sport's Twitter account.

[Table 4 near here]

\section{Deployment of multimedia elements (RQ3)}

As Table 5 indicates, @BBCSport uses a wide range of multimedia elements (links, photographs, videos, audios, and photo galleries), being fully aware of their power when it comes to mobilising users' attention and enhancing the completeness and quality of the information provided (Naraine and Parent, 2017). Only 78 tweets $(0.72 \%$ of the sample) did not include multimedia elements. The category 'link plus photograph' was the most common across the sample $(82.71 \%)$, followed by a video with or without a link. While photographs and videos were very relevant as key ingredients in enhancing news, audio still appears as an emerging format on the Twitter timeline; audio represented only $0.07 \%$ of BBC's tweets. This finding was not anticipated, considering the extensive audio output offered by BBC Radio 5 Live and BBC Radio 5 Live Sports Extra (BBC, 2020).

[Table 5 near here]

It is worth noting that photographs, videos, links, and other multimedia resources were consistently used across the sample, regardless of gender or the ability or disability of the athletes covered (Table 6).

[Table 6 near here]

Multimedia elements did not hinder the visibility and value of underrepresented sports, sportswomen, and athletes with disabilities. Thus, multimedia elements facilitated audiences' appreciation of protagonists, which tends to be, off the radar, in sports media.

\section{Discussion and conclusion}

In the present landscape, the wider commodification of the sports media market, characterised by the domination of pay-TV broadcasters and telecommunications operators, has eroded PSM's ability to maintain free-to-air access to sporting events (Ramon and Haynes, 2019; Smith, 2017). However, digital transformations have 
revolutionised the production, transmission, and consumption of sports across countless media platforms and channels (Serazio, 2019), offering PSM new opportunities to broaden the agenda and enhance cultural citizenship.

The BBC has historically contributed to advancing cultural citizenship through sports. The Corporation has provided public value by positioning sports as an essential component of national culture (Boyle, 2006). Through its radio and television output, the $\mathrm{BBC}$ has been instrumental in establishing and preserving a calendar of major sporting events while cultivating an appreciation of a diverse range of sporting practices rooted in the nation's life (Haynes, 2016; Huggins, 2007; Smith, 2017; Whannel, 1992). As 'the analogue world recedes and the digital universe beckons' (Rowe, 2014: 181), the BBC is currently at a critical juncture. In response to the ongoing challenges and limitations, it has expanded its digital services, offering users a range of sports content across countless platforms and devices. On social media, the larger presence and following of BBC Sport uncover questions about whether the Corporation is using those spaces to promote diversity.

This research has indicated that the BBC delivers a continuous stream of sports information on Twitter, leveraging the power of multimedia elements to mobilise users' attention and provide the most comprehensive coverage possible. Nevertheless, this analysis illustrates that @BBCSport contributes to strengthening, rather than counteracting, the long-standing agenda imbalances present in sports media. The results demonstrate that in a post-scarcity media age, 'volume does not necessarily guarantee diversity' (Andrejevic, 2013: 128). Digital channels have allowed the volume of sports content to expand, but the agenda has not widened: social media has intensified footballcentrism alongside the dominance of other highly commodified disciplines and protagonists. While minority sports, sportswomen, and athletes with disabilities are featured in the agenda, their position is diluted due to the overabundance of content distributed across various social media channels.

Such imbalances raise questions about the concentration of symbolic power in the digital age. Arguably, if the bulk of content distributed is about 'the same established band of professional sports teams and leagues that have long held popular attention' (Hutchins and Rowe, 2012: 69), opportunities for advancing cultural citizenship in the digital age (Goode, 2010; Hermes, 2020; Wu, 2013) cannot be fully met. Presently, many sporting practices, events, and protagonists do not receive wider visibility and recognition that social media platforms can easily afford. 
The football-driven, male-centred, and able-bodied agenda displayed by @BBCSport is consistent with the output delivered by other PSM corporations across Europe (Rojas-Torrijos and Ramon, 2021). Thus, these findings should be interpreted acknowledging the complex environment in which the $\mathrm{BBC}$ and other public corporations presently operate. As Steiner, Magin, and Stark (2019: 104) highlight, PSM are 'forced to adapt to the highly commercialized SNS, whose aim is to satisfy consumers instead of citizens'. In the search for young demographics - the under 35 age group - (Bradshaw, 2020), PSM 'find themselves pressured to publish stories that appeal to these platforms' algorithms so that they are more likely to cut through a cluttered media environment and get noticed by audiences' (Nelson, 2019: 5). In the process, 'normative standards such as diversity come into conflict with commercial aims, including popularity and saleability' (Steiner et al., 2019: 104). In the case of the BBC, the search for increased engagement on Twitter translated to a narrow approach that reproduced the centrality of dominant sports, particularly of those capable of steering users to linear or online broadcasting transmissions.

While conditioning factors and trade-offs linked to the nature of digital platforms cannot be ignored (Donders, 2019), PSM must consider the far-reaching consequences of restricting the exposure of minority sports, sportswomen, and athletes with disabilities on their Twitter timelines. Public corporations cannot forget that 'media sport is an institutional context that continuously generates cultural meanings linked to effects in the social world, symbolic relations, media systems, and the marketplace' (Hutchins, 2019: 474). Although certain sports have always maintained a prominent position in the BBC agenda (Whannel, 1992), the ongoing emphasis on hyper-commodified sports is at the expense of other disciplines, which are secluded from the same social recognition and institutional support. Likewise, the limited visibility of sportswomen and athletes with disabilities reinforces the idea that sport is a masculine and able-bodied domain, hindering the opportunities for these long-lasting perceptions to be challenged. Overall, if PSM mostly embrace the 'economic zone' (Smith, 2017: 206) in their social media output, a valuable opportunity to promote diversity will be lost (Davie, 2020).

Given that the $\mathrm{BBC}$ does not rely on user metrics as much as other commercial media outlets which require private funding and advertising to be financially sustainable, the Corporation should supply a distinctive service (Cushion, 2021) that pays 'particular regard to the need to reflect underrepresented communities' (DCMS, 2016: 9). In complying with its public remit,@BBCSport agenda should not incur such evident 
inequalities when representing different sports and protagonists, including sportswomen and athletes with disabilities. Specifically, regarding the latter, covering disability sport responsibly does not only include reporting about results in major events such as the Paralympic Games but also providing a stable following of its protagonists through features, profiles, and interviews. Providing a steady exposure to athletes with disabilities should be of utmost importance for the BBC, considering the country's history with disability sport (Brittain, 2012) and all-time performance at the Paralympics.

The insights gleaned from the analysis signal that in an increasingly commercialised environment, PSM should reframe their social media strategies to adequately contribute to fostering cultural citizenship. PSM outlets should take advantage of social media to promote a diverse menu that promotes inclusion rather than exclusion. Beyond increasing the exposure to non-mainstream sports, sportswomen, and athletes with disabilities during major sporting events, PSM should play a distinctive role by sustaining the engine consistently. Considering its influential role, the $\mathrm{BBC}$ should be at the forefront of such a transformation. Broadening the range of disciplines covered and exposing the profiles of unfamiliar protagonists is essential in building a comprehensive sporting media coverage, which not only informs, entertains, and educates citizens but also empowers them.

As with any study, this project has limitations. First, it only considered one platform, Twitter, excluding others. Thus, further research is required to establish whether these findings can be generalised to other social media networks such as Facebook and Instagram. Second, this research provided a radiography of BBC Sport's Twitter output during the timeframe of the observation, so a season aspect might be considered in the sample. However, if we consider the consistency of sports coverage in Great Britain, prioritising the same sports throughout the year (Boyle, 2006), this study offers a compelling picture of the lack of agenda diversity offered by @BBCSport.

There are several possibilities for future research which emanate from this article. First, further studies could compare and contrast the @BBCSport agenda on Twitter with the output delivered by other PSM in Europe and beyond. Second, considering the unparalleled impact of COVID-19 in the world of sports (Rowe, 2020), future studies should trace the imbalances in the sports agenda on Twitter during the pandemic to examine the extent to which the patterns observed before the outbreak continued or changed. Third, future research could scrutinise how Twitter is perceived and employed 
by heavy users as a second or first screen while viewing live events, tracing how different types of output affect PSM engagement rates.

Furthermore, conducting in-depth interviews with social media editors and journalists at BBC Sport and other PSM would be beneficial to understanding how Twitter is reshaping the traditional role of sports media professionals and their relationship with sources and fans. These conversations can provide researchers with nuances of detail on how PSM use Twitter to disseminate content globally while contributing to preserving and enhancing cultural citizenship.

\section{References}

Adá-Lameira A and Rodríguez-Castro Y (2020) The presence of female athletes and non-athletes on sports media Twitter. Feminist Media Studies.

\section{https://doi.org/10.1080/14680777.2020.1732439}

Andrejevic M (2013) Public service media utilities: Rethinking search engines and social networking as public goods. Media International Australia 146(1): 123-132. https://doi.org/10.1177/1329878x1314600116

Bailey M (2019) Back to the future: The uses of television in the digital age. Journal of British Cinema and Television 16(2): 146-169.

\section{https://doi.org/10.3366/jbctv.2019.0466}

BBC (2019) BBC Group Annual Report and Accounts 2018/19. London, UK: BBC. BBC (2020) BBC Group Annual Report and Accounts 2019/20. London, UK: BBC.

Bertling C and Schierl T (2008) Disabled sport and its relation to contemporary cultures of presence and aesthetics. Sport in History 28(1): 39-50. https://doi.org/10.1080/17460260801889202

Billings A and Angelini J (2019) Equity achieved? A longitudinal examination of biological sex representation in the NBC Olympic telecast (2000-2018).

Communication \& Sport 7(5): 551-564.

https://doi.org/10.1177/2167479519863652

Boehmer J (2017) The use of social media in sports. In: Rojas-Torrijos JL(ed)

Periodismo deportivo de manual. Valencia: Tirant, pp.297-319.

Boyle R (2006) Sports Journalism. Context and Issues. London: Sage.

Boyle R (2017) Sports Journalism. Changing journalism practice and digital media.

Digital Journalism 5(5): 493-495.

\section{https://doi.org/10.1080/21670811.2017.1281603}


Boyle R and Haynes R (2009) Power Play. Sport, the Media and Popular Culture.

Edinburgh: Edinburgh University Press.

Bradshaw T (2020) Auntie on the sports journalism dance floor. In: Mair J and

Bradshaw T (eds) Is the BBC in peril? Does it deserve to be?. Goring, UK: Bit-

Sized Books, pp.80-84.

Brittain I (2012) From Stoke Mandeville to Stratford. A history of the Summer

Paralympic Games. Champaign, Illinois: Common Ground Publishing.

Brittain I (2017) Communicating and managing the message: Media and media representation of disability and Paralympic sport. In: Darcy S, Frawley S and Adair

D (eds) Managing the Paralympics. London: Palgrave Macmillan, pp.241-262.

Broussard R (2020) "Stick to sports" is gone: A field theory analysis of sports

journalists' coverage of socio-political issues. Journalism Studies 21(12): 1627-

1643. https://doi.org/10.1080/1461670X.2020.1785323

BT (2019) BT Group PLC Annual Report 2019. London, UK: BT Group.

Coche R (2015) The amount of women's sports coverage on international sports news websites' home pages. Electronic News 9(4): 223-241.

https://doi.org/10.1177/1931243115604882

Coche R (2021) A new era? How the European ESPN covered the 2019 women's

World Cup online. International Review for the Sociology of Sport.

https://doi.org/10.1177/1012690221992242

Cooky C, Council LD, Mears MA and Messner MA (2021) One and done: The long eclipse of women's televised sports (1989-2019). Communication \& Sport.

https://doi.org/10.1177/21674795211003524

Cunningham NR and Eastin MS (2017) Second screen and sports: A structural investigation into team identification and efficacy. Communication \& Sport 5(3): 288-310. https://doi.org/10.1177/2167479515610152

Cushion S (2021) Are public service media distinctive from the market? Interpreting the political information environments of $\mathrm{BBC}$ and commercial news in the United Kingdom. European Journal of Communication 1-18.

https://doi.org/10.1177/02673231211012149

Cwynar C (2017) On thin ice: Hockey Night in Canada and the future of national public service media. International Communication Gazette 79(2): 135-147.

https://doi.org/10.1177/1748048516689194 
Davie T (2020) BBC outlines plans to accelerate diverse representation on and offscreen. BBC.com Media Centre. Retrieved from:

https://www.bbc.com/mediacentre/2020/creative-diversity-plan

Department for Culture, Media and Sport (DCMS) (2016) Copy of Royal Charter for the continuance of the British Broadcasting Corporation. Retrieved from: http://downloads.bbc.co.uk/bbctrust/assets/files/pdf/about/how_we_govern/2016/c harter.pdf

Donders K (2019) Public service media beyond the digital hype: Distribution strategies in a platform era. Media, Culture and Society 41(7): 1011-1028. https://doi.org/10.1177/0163443719857616

English P (2018) Sports Journalism. In: Nussbaum JF (ed) Oxford Research Encyclopedia of Communication. Oxford: Oxford University Press, pp.1-18. French L and Le Clair JM (2018) Game Changer? Social Media, Representations of Disability and the Paralympic Games. In: Brittain I and Beacom A (eds) The Palgrave Handbook of Paralympic Studies. London: Palgrave Macmillan, pp.99121.

Goddard P (2017) 'Distinctiveness' and the BBC: A new battleground for public service television? Media, Culture \& Society 39(7): 1089-1099.

https://doi.org/10.1177/0163443717692787

Goode L (2010) Cultural citizenship online: the Internet and digital culture. Citizenship Studies 14(5): 527-542. https://doi.org/10.1080/13621025.2010.506707

Grimmer CG and Horky T (2018) Twitter and sports journalism in Germany: Application and networks during the Sochi 2014 Winter Olympics. Journal of Media and Communication Studies 10(6): 65-77.

https://doi.org/10.5897/JMCS2017.0596

Hardin M, Dodd JE and Lauffer K (2006) Passing it on: The reinforcement of male hegemony in sports journalism textbooks. Mass Communication and Society 9(4): 429-446. https://doi.org/10.1207/s15327825mcs0904_3

Haynes R (2016) BBC Sport in Black and White. London, UK: Palgrave Macmillan UK. Haynes R and Robeers T (2019) The need for speed? A historical analysis of the BBC's post-war broadcasting of motorsport. Historical Journal of Film, Radio and Television 40(2): 407-423. https://doi.org/10.1080/01439685.2019.1628418 Hermes J (2005) Re-reading Popular Culture. Malden: Blackwell. 
Hermes J (2020) Tracing cultural citizenship online. Continuum 34(3): 314-327. https://doi.org/10.1080/10304312.2020.1764776

Hesmondhalgh D and Lotz AD (2020) Video screen interfaces as new sites of media circulation power. International Journal of Communication 14: 386-409.

Horky T (2021) No sports, no spectators - no media, no money? The importance of spectators and broadcasting for professional sports during COVID-19. Soccer \& Society 22(1-2): 96-102. https://doi.org/10.1080/14660970.2020.1790358

Horky T and Nieland JU (2013) The International Sports Press Survey 2011. Norderstedt: Books on Demand GmbH.

Howe PD and Silva CF (2018) The fiddle of using the Paralympic Games as a vehicle for expanding [dis]ability sport participation. Sport in Society 21(1): 125-136. https://doi.org/10.1080/17430437.2016.1225885

Huggins M (2007) BBC radio and sport 1922-39. Contemporary British History 21(4): 491-515. https://doi.org/10.1080/13619460601060512

Hull K and Lewis NP (2014) Why Twitter displaces broadcast sports media: A model. International Journal of Sport Communication 7(1): 16-33. https://doi.org/10.1123/IJSC.2013-0093

Hutchins B (2019) Mobile media sport: The case for building a mobile media and communications research agenda. Communication and Sport 7(4): 466-487. https://doi.org/10.1177/2167479518788833

Hutchins B (2020) COVID-19: Despite its flaws, sport's significance runs deep in society. Lens, Monash University. Retrieved from: https://lens.monash.edu/@politics-society/2020/04/17/1380104/coronavirusconnection-and-no-sport

Hutchins B, Li B and Rowe D (2019) Over-the-top sport: Live streaming services, changing coverage rights markets and the growth of media sport portals. Media, Culture, \& Society 41(7): 975-994. https://doi.org/10.1177/0163443719857623

Hutchins B and Rowe D (2009) From broadcast scarcity to digital plenitude: The changing dynamics of the media sport content economy. Television \& New Media 10(4): 354-370. https://doi.org/10.1177/1527476409334016

Hutchins B and Rowe D (2012) Sport beyond television: The Internet, digital media and the rise of networked media sport. New York: Routledge. 
Kay J (2010) A window of opportunity? Preliminary thoughts on women's sport in postwar Britain. Sport in History 30(2): 196-217.

https://doi.org/10.1080/17460263.2010.481206

Krippendorf K (2019) Content Analysis. An Introduction to Its Methodology (4th Edition). London: Sage.

Lopez-Gonzalez H, Stavros C and Smith A (2019) The transition of second-screen devices to first screen status in sport viewing. Sport in Society 22(12): 2077-2088. https://doi.org/10.1080/17430437.2018.1554649

Masduki (2017) Political economy of sport broadcasting: Assessing Indonesian PSB policy in sport broadcasting. International Communication Gazette 79(2): 162174. https://doi.org/10.1177/1748048516689196

McCombs M (2005) A look at agenda-setting: Past, present, and future. Journalism Studies 6(4): 543-557. https://doi.org/10.1080/14616700500250438

Naraine ML and Parent MM (2017) This is how we do it: A qualitative approach to national sport organizations' social-media implementation. International Journal of Sport Communication 10(2): 196-217. https://doi.org/10.1123/IJSC.2017-0006

Nelson JL (2019) The next media regime: The pursuit of 'audience engagement' in journalism. Journalism. https://doi.org/10.1177/1464884919862375

O'Neill D and Mulready M (2015) The invisible woman? A comparative study of women's sports coverage in the UK national press before and after the 2012 Olympic Games. Journalism Practice 9(5): 651-668.

https://doi.org/10.1080/17512786.2014.965925

Parnell D, Widdop P, Bond A and Wilson R (2020) Covid-19, networks and sport. Managing Sport and Leisure, 1-7.

https://doi.org/10.1080/23750472.2020.1750100

Pawley L (2008) Cultural Citizenship. Sociology Compass 2(2): 594-608. https://doi.org/10.1111/j.1751-9020.2008.00094.x

Pullen E, Jackson D and Silk M (2020a) (Re-)presenting the Paralympics: Affective nationalism and the "able-disabled." Communication and Sport 8(6): 715-737. https://doi.org/10.1177/2167479519837549

Pullen E, Jackson D and Silk M (2020b) Watching disability: UK audience perceptions of the Paralympics, equality and social change. European Journal of Communication 35(5): 469-483. https://doi.org/10.1177/0267323120909290 
Ramon X and Haynes R (2019) Sports coverage on BBC ALBA: Content, value, and position in the Scottish broadcasting landscape. Communication and Sport 7(2): 221-243. https://doi.org/10.1177/2167479518760485

Ramon X and Rojas-Torrijos JL (2018) Accountable sports journalism. Building up a platform and a new specialised code in the field. Ethical Space 15(1-2): 15-28.

Reichart L, Pegoraro A and Cruikshank SA (2019) Tweet, retweet, favorite: The impact of Twitter use on enjoyment and sports viewing. Journal of Broadcasting \& Electronic Media 63(1): 94-110. https://doi.org/10.1080/08838151.2019.1568805 Rojas-Torrijos JL (2012) La futbolización de la información deportiva. Un estudio de casos de cuatro diarios deportivos europeos. Revista Comunicação \& Cultura 13: 77-95. https://doi.org/10.34632/comunicacaoecultura.2012.629

Rojas-Torrijos JL and Ramon X (2021) Exploring agenda diversity in European public service media sports desks: A comparative study of underrepresented disciplines, sportswomen and disabled athletes' coverage on Twitter. Journalism Studies 22(2): 225-242. https://doi.org/10.1080/1461670X.2020.1809497

Røssland LA (2017) Sports - nation - television: The cultural dimension of the Listed Events history in Norway. International Communication Gazette 79(2): 148-161. https://doi.org/10.1177/1748048516689195

Rowe D (2004) Watching brief: Cultural citizenship and viewing rights. Sport in Society 7(3): 385-402. https://doi.org/10.1080/1743043042000291703

Rowe D (2013) Reflections on communication and sport: On nation and globalization.

Communication \& Sport 1(1-2): 18-29.

https://doi.org/10.1177/2167479512467328

Rowe D (2014) Events of National Importance and Cultural Significance. In: Scherer J and Rowe D (eds) Sport, Public Broadcasting, and Cultural Citizenship. Abingdon: Routledge, pp.166-187.

Rowe D (2018) Cultural citizenship, media and sport in contemporary Australia.

International Review for the Sociology of Sport 53(1): 11-29.

https://doi.org/10.1177/1012690216641147

Rowe D (2020) Subjecting pandemic sport to a sociological procedure. Journal of Sociology 56(4): 704-713. https://doi.org/10.1177/1440783320941284

Serazio M (2019) The Power of Sports. Media and Spectacle in American Culture. New York: New York University Press. 
Schallhorn C and Kunert J (2020) Football without football: Creativity in German football coverage by TV broadcasters and clubs during the coronavirus crisis. International Journal of Sport Communication 13(3): 514-522. https://doi.org/10.1123/ijsc.2020-0234

Schell LA and Rodriguez S (2000) Our sporting sisters: How male hegemony stratifies women in sport. Women in Sport and Physical Activity Journal 9(1): 15-34. https://doi.org/10.1123/wspaj.9.1.15

Scherer J and Sam MP (2012) Public broadcasting, sport and cultural citizenship: Sky's the limit in New Zealand? Media, Culture and Society 34(1): 101-111. https://doi.org/10.1177/0163443711429234

Scherer J and Whitson D (2009) Public broadcasting, sport, and cultural citizenship: The future of sports on the Canadian Broadcasting Corporation? International Review for the Sociology of Sport 44(2-3): 213-229. https://doi.org/10.1177/1012690209104798

Schoch L (2020) The gender of sports news: Horizontal segregation and marginalization of female journalists in the Swiss press. Communication and Sport 1-21. https://doi.org/10.1177/2167479520951162

Sky (2018). Annual Report 2018. Isleworth: Sky plc.

Smith P (2016) Television sports rights beyond the West: The cases of India and South Africa. Global Media and Communication 12(1): 67-83.

https://doi.org/10.1177/1742766515626829

Smith P (2017) Playing under pressure: Sport, public service broadcasting and the British Broadcasting Corporation. International Communication Gazette 79(2): 203-216. https://doi.org/10.1177/1748048517692907

Solves J, Pappous A, Rius I and Kohe GZ (2019) Framing the Paralympic Games: A mixed-methods analysis of Spanish media coverage of the Beijing 2008 and London 2012 Paralympic Games. Communication and Sport 7(6): 729-751. https://doi.org/10.1177/2167479518808237

Steiner M, Magin M and Stark B (2019) Uneasy bedfellows. Comparing the diversity of German public service news on television and on Facebook. Digital Journalism 7(1): 100-123. https://doi.org/10.1080/21670811.2017.1412800 Stevenson N (2003) Cultural Citizenship: Cosmopolitan Questions. Maidenhead: Open University Press. 
Sweney M (2021) “There is tension everywhere”: Premier League on the back foot as rights auction nears. Retrieved from:

https://www.theguardian.com/media/2021/jan/11/tension-everywhere-premierleague-back-foot-uk-tv-rights-auction-nears

Tulloch C and Ramon X (2017) Take five: How Sports Illustrated and L'Équipe redefine the Long Form Sports Journalism genre. Digital Journalism 5(5): 652672. https://doi.org/10.1080/21670811.2016.1263159

Turner B S (2001) Outline of a general theory of cultural citizenship. In: Stevenson N (ed.) Culture and citizenship. London: Sage, pp. 11-32.

Van Es K and Poell T (2020) Platform imaginaries and Dutch public service media. Social Media and Society 6(2). https://doi.org/10.1177/2056305120933289

Whannel G (1992) Fields in Vision. Television Sport and Cultural Transformation. London, UK: Routledge.

Whannel G (2009) Television and the transformation of sport. The ANNALS of the American Academy of Political and Social Science 625(1): 205-218. https://doi.org/10.1177/0002716209339144

Wimmer RD and Dominick JR (2011) Mass Media Research: An Introduction. Wadsworth: Cengage Learning.

Woodhouse J (2020) Briefing Paper: Broadcasting: listed sporting events. London: House of Commons Library. Retrieved from: https://commonslibrary.parliament.uk/research-briefings/sn00802/

Wu J C (2013) Cultural citizenship at the intersection of television and new media. Television \& New Media 14(5): 402-420. https://doi.org/10.1177/1527476412446089 
Table 1. Volume and frequency of the analysed tweets

\begin{tabular}{ll}
\hline Analysed tweets & 10,821 \\
Tweets per day & 118.91 \\
Original content & 8,616 \\
\% of tweets being original content & 79.62 \\
Retweets & 2,061 \\
\% of tweets being retweets & 19.05 \\
Replies & 114 \\
\% of tweets being replies & 1.33 \\
\hline
\end{tabular}

Source: Authors' analysis.

Table 2. Sports agenda

\begin{tabular}{|c|c|c|}
\hline Sports & $\mathbf{N}$ & $\%$ \\
\hline Association Football & 6,719 & 62.09 \\
\hline Rugby & 878 & 8.11 \\
\hline Cricket & 747 & 6.90 \\
\hline Tennis & 450 & 4.16 \\
\hline Boxing & 363 & 3.35 \\
\hline Multisport & 257 & 2.38 \\
\hline Motorsport & 241 & 2.23 \\
\hline American Football & 143 & 1.32 \\
\hline Athletics & 130 & 1.20 \\
\hline Basketball & 129 & 1.19 \\
\hline Snooker & 122 & 1.13 \\
\hline Fighting & 120 & 1.11 \\
\hline Cycling & 76 & 0.70 \\
\hline Golf & 61 & 0.56 \\
\hline Horse Racing & 59 & 0.55 \\
\hline Darts & 52 & 0.48 \\
\hline Skiing & 25 & 0.23 \\
\hline Swimming & 25 & 0.23 \\
\hline Hockey & 21 & 0.19 \\
\hline Badminton & 18 & 0.17 \\
\hline Snowboarding & 16 & 0.15 \\
\hline Ice Hockey & 14 & 0.13 \\
\hline Gymnastics & 13 & 0.12 \\
\hline Bowling & 11 & 0.10 \\
\hline
\end{tabular}




\begin{tabular}{|c|c|c|}
\hline Netball & 11 & 0.10 \\
\hline Figure Skating & 9 & 0.08 \\
\hline Curling & 8 & 0.07 \\
\hline Fitness & 8 & 0.07 \\
\hline Rowing & 8 & 0.07 \\
\hline Judo & 7 & 0.06 \\
\hline Table Tennis & 7 & 0.06 \\
\hline Wheelchair Rugby & 7 & 0.06 \\
\hline Skateboarding & 6 & 0.06 \\
\hline Triathlon & 6 & 0.06 \\
\hline Bobsleigh & 5 & 0.05 \\
\hline Speed Skating & 5 & 0.05 \\
\hline Canoeing & 4 & 0.04 \\
\hline Taekwondo & 4 & 0.04 \\
\hline Baseball & 3 & 0.03 \\
\hline Climbing & 3 & 0.03 \\
\hline Wheelchair Basketball & 3 & 0.03 \\
\hline Australian Football & 2 & 0.02 \\
\hline eSports & 2 & 0.02 \\
\hline Luge & 2 & 0.02 \\
\hline Powerlifting & 2 & 0.02 \\
\hline Sleigh Riding & 2 & 0.02 \\
\hline Surfing & 2 & 0.02 \\
\hline Wheelchair Motocross & 2 & 0.02 \\
\hline Other Winter Sports & 2 & 0.02 \\
\hline Biathlon & 1 & 0.01 \\
\hline Boccia & 1 & 0.01 \\
\hline Dragon Boating & 1 & 0.01 \\
\hline Ice Skating & 1 & 0.01 \\
\hline Kayaking & 1 & 0.01 \\
\hline Modern Pentathlon & 1 & 0.01 \\
\hline Sailing & 1 & 0.01 \\
\hline Ski Jumping & 1 & 0.01 \\
\hline Sport Climbing & 1 & 0.01 \\
\hline Wrestling & 1 & 0.01 \\
\hline Yukigassen & 1 & 0.01 \\
\hline Total & 10,821 & 100.00 \\
\hline
\end{tabular}

Source: Authors' analysis. 
Table 3. Gender of protagonists

\begin{tabular}{lrr}
\hline & N & \multicolumn{1}{c}{$\%$} \\
\hline Female & 1,160 & 10.72 \\
Male & 9,048 & 83.62 \\
Mixed & 613 & 5.66 \\
\hline Total & 10,821 & 100.00 \\
\hline
\end{tabular}

Source: Authors' analysis.

Table 4. Presence of disability sport in the coverage

\begin{tabular}{lrr}
\hline & \multicolumn{1}{c}{ N } & \multicolumn{1}{c}{$\%$} \\
\hline Disability sport & 136 & 1.26 \\
Non-Disability sport & 10,685 & 98.74 \\
\hline Total & 10,821 & 100.00 \\
\hline
\end{tabular}

Source: Authors' analysis.

Table 5. Deployment of multimedia elements

\begin{tabular}{lrr}
\hline & \multicolumn{1}{c}{$\mathbf{N}$} & \multicolumn{1}{c}{$\%$} \\
\hline Audio & 8 & 0.07 \\
Link & 139 & 1.28 \\
Link + Photograph & 8,950 & 82.71 \\
Link + Video & 832 & 7.69 \\
Link + Audio & 26 & 0.24 \\
No multimedia & 78 & 0.72 \\
Photo gallery & 37 & 0.34 \\
Photograph & 189 & 1.75 \\
Survey & 10 & 0.09 \\
Video & 552 & 5.10 \\
\hline Total & 10,821 & 100.00 \\
\hline Source: Authors & &
\end{tabular}

Source: Authors' analysis. 
Table 6. Multimedia elements used to present sportswomen and athletes with disabilities

\begin{tabular}{|c|c|c|c|c|}
\hline & \multicolumn{2}{|c|}{ Sportswomen } & \multicolumn{2}{|c|}{ Athletes with disabilities } \\
\hline & $\mathbf{N}$ & $\%$ & $\mathbf{N}$ & $\%$ \\
\hline Audio & 0 & 0.00 & 0 & 0.00 \\
\hline Link & 22 & 1.90 & 3 & 2.21 \\
\hline Link + Photograph & 942 & 81.21 & 121 & 88.97 \\
\hline Link + Video & 125 & 10.78 & 4 & 2.94 \\
\hline Link + Audio & 2 & 0.17 & 0 & 0.00 \\
\hline No multimedia element & 1 & 0.09 & 1 & 0.74 \\
\hline Photo gallery & 2 & 0.17 & 0 & 0.00 \\
\hline Photograph & 13 & 1.12 & 2 & 1.47 \\
\hline Survey & 53 & 4.57 & 0 & 0.00 \\
\hline Video & 0 & 0.00 & 5 & 3.68 \\
\hline Total & 1,160 & 100.00 & 136 & 100.00 \\
\hline
\end{tabular}

Source: Authors' analysis. 